\title{
Corporate Citizenship Behaviour and Rural Livelihoods: A Study on Multinational Corporations in Sri Lanka
}

\author{
Sachin Wijayasinghe \\ University of Sri Jayewardenepura, Sri Lanka \\ Vilani Sachitra \\ University of Sri Jayewardenepura, Sri Lanka
}

\begin{abstract}
Corporate citizenship seems a new conceptualization of the role of business in society. Disparity between rural and urban economy is growing and it is essential for multinational companies to address the issues benchmarking best practices. MNCs enter a nation with numerous guarantees but are they equipped for accomplishing objectives as a corporate citizen? Although the role of MNCs on local firms has been measured at different industry levels, rural livelihood perspective is unkempt in developing economies. The study aims to identify the roles of MNCs in enhancing the rural livelihoods of the dairy farmers in Sri Lanka. The study was based on an exploratory approach, adopting a qualitative research design with a thematic data analysis. Data were collected through semistructured interviews from twenty-five dairy farmers who were directly engaging with MNC subsidiaries operating in the rural community of Sri Lanka. The MNC has been able to enhance the rural livelihoods of the dairy farmers through generating of job opportunities and replacing conventional practices with modern technology, identifying the importance of knowledge management, understanding the value of quality, adhering to policies, standards and guidelines along with maintaining proper documentations and improving the return on invested capital. However, the MNC has failed to build strong relationships with local authorities and struggled to promote dairy farming as a main source of income. MNCs exercises in the developing context is still being contended and coordinating and compiling a policy framework with the local authorities could play a significant role in shaping the livelihoods of the dairy farmers.
\end{abstract}

\section{Corresponding Author:}

Sachin Wijayasinghe is an Assistant Lecturer at the Department of Commerce, University of Sri Jayewardenepura, Sri Lanka. E-mail: slw1424@gmail.com 
Keywords: Dairy Farming, Multinational Corporation, Rural livelihoods, Corporate Citizenship

\section{Introduction}

Livelihood perspective has proved to be interesting for scholars from different disciplines and this leads to conducting the studies dealing with a diversity of themes and focusing on diverse categories of people all over the globe (Addinsall et al., 2019; Naithani and Saha, 2020). While the roots of the livelihood approach thus lie in the 1980s and early 1990s, the basic ideas have been further developed through contributions made by scholars from different disciplines over the years. In line with that, livelihoods can be devoted to various fields of development practices such as those relating to locales (rural or urban livelihoods), occupations (farming, pastoral or fishing livelihoods), social difference (gendered, agedefined livelihoods), directions (livelihood pathways, trajectories), dynamic patterns (sustainable or resilient livelihoods) and many more (Scoones, 2009). Freeman (1975) insists that livelihood is used in a rather concrete manner to describe the ways in which people make a living, and mainly points to the economic resource base people have at their disposal for doing this. Thus, it is quite conceivable that livelihood comprises the capabilities, assets (including both material and social resources) and activities required for a means of living (Chambers and Conway, 1992).

Prior studies argue that as business organizations operate within the social arenas and make profits from people in societies, they should behave ethically and take care of societies and their livelihood (Dunfee, 2006; Hiseh, 2009, Tsoi, 2010). A business firm is considered as a citizen and with the advancements in the economic and social environment through globalization, a new interest in the concept of a business firm as a citizen has appeared. With the rise of global giants and achievement of economies of scale through technological improvements while exercising comparative advantage by decreasing cost, the corporate institutions has received more economic and social power. (Garriga and Mele, 2004). Corporate citizenship is the role to be played by the corporate body in the society and the corporate institutions are vested with the responsibilities to act when the government fails to take care of the society (Arato et al., 2016). The corporate citizenship theory focuses on protecting the rights and responsibilities vested for partnering with the company and proposes that business has a responsibility to uplift the local community while improving the livelihoods of 
the stakeholders partnering with the company. Arato et al. (2016) emphasized that to become a good corporate citizen following over-regulated processes will hinder social benefits to the local community and therefore corporate citizenship projects should be carefully selected and should not be executed as a marketing tool. As Arato insist, establishing an effective communication channel, promoting health and nutrition among the community, effort of proving micro finances, creation of employment opportunities, educating technical and operational aspects of the entity were main corporate citizenship activities.

Concerning the business organizations, multinational corporations (MNCs) have greater visibility than local companies and usually face high media exposure and serious public scrutiny, their activities are more important than those of local organizations (Fougere and Solitander, 2009; Sotorrio and Sanchez, 2010). MNCs are organizations that operate in different countries face multiple challenges that are unique to different national contexts (Kolk et al., 2010). MNCs have contributed in transferring valuable knowledge and technology enjoying higher revenue by transforming high quality raw materials into value added goods reducing cost through cheap labour mainly. It is the responsibility of MNCs to contribute to the socio-economic development of the host nation while striving to achieve its own goals and objectives. (Williams et al., 2017).

As MNCs have more public exposure than local organizations, they need to be more sensitive towards rural livelihood. In certain cases, the social performance of MNCs appears to be commendable and these MNCs are considered social transformers (Ite, 2004; Engle, 2007; Nwoke, 2016) where MNCs have displayed progressive leadership and have played a pioneering role in establishing standards for ethical and moral responsibilities in terms of job creation, capacity building, technology transfer, and promoting. Profitability concepts have driven MNCs to exploit nature, losing core values of protecting the environment and protecting social values. MNCs benefit by procuring quality raw materials and cheap labour locally exercising dominance in local operations.

Sri Lanka, as an emerging economy, has experienced foreign direct investments and an arrival of MNCs in recent years. It is assumed that MNCs in Sri Lanka are trying to implement some activities to uphold rural livelihood, while boosting their corporate images. The developmental impact of MNCs in terms of industrial growth, managerial knowledge transfer, and development of host country employees' skill needs to be well documented and applauded by civil society. However, the social transformation/livelihood improvement activities of those 
MNCs are still unknown and unrecognized in society. It is very important MNCs to invest on rural economy subsequent to achieving objectives of the company.

Leading MNC in Sri Lanka contributes Rs. 8Bn to the rural community enriching dairy farmers and coconut farmers catering to 13 million consumers of the country with the intention of developing Sri Lanka rural community while improving the dairy industry especially helping the country to be self-sufficient in production (Annual Report Nestle Lanka PLC, 2018). With the contribution of the MNC there is a gradual growth reaching the mark of 450 million litres in production for the years 2018 and 2019. Wayamba and Northern regions are the biggest contributors to the dairy farming industry collectively managing 1500 chilling centres out of 3469 and Kurunegala district alone handles 856 centres (Department of Census and Statistics, 2020) According to the Household Income and Expenditure Survey 2016 conducted by the Department of Census and Statistics $82 \%$ of poor people came from rural areas while Northern province accounted to $12 \%$ and North Western (Wayamba) accounted to $10 \%$. Previous literature discussed the contributions of MNCs improving the rural livelihoods and the authors wanted to explore whether the existence of the MNC has improved the situation or not.

The purpose of this paper is to investigate the role of MNCs' activities on rural livelihoods in Sri Lanka. The theoretical foundation of corporate citizenship facilitates the study objective of identification of roles of MNCs to uplift the rural livelihoods. Sri Lanka has been a self-sufficient nation since ancient days agriculture sector being the pillar strengthening the rural economy contributing $7.5 \%$ to the national GDP and 30\% of employability (Central Bank Report, 2018). Dairy farmers are being mainly encouraged by MNCs in Sri Lanka, they directly purchase quality raw materials from the farmers securing a fixed annual income while protecting local producers and encouraging local products. Having said so, the study indents to identify the roles of MNCs in enhancing rural livelihoods of dairy farmers in Sri Lanka.

\section{Literature Review}

The concept of livelihood has gained popularity of poverty and development issues among both scholars and policy makers. Therefore, livelihoods perspectives have been central to rural development thinking and practice, specifically in developing countries (Kaag et al. 2013; Odebode, 2019). Rural areas become the backbone of most developing countries by creating jobs, supplying labour, food and raw materials and maintaining the cultural heritage. 
Although they contribute to overall economic growth, they are still characterized by poverty, unemployment, inequalities, food insecurity, etc. In this sense, livelihood offers an important lens for looking at/ to perceive complex rural development questions (Igwe et al., 2019). As Scoones and Wolmer (2003) insist, attention needs to be drawn for making the links from rural people's livelihood to institutional and policy framing at national and international levels. It is vital to rethink, reengage and strengthen the livelihood perspective for dynamic challenges, thus, livelihood perspectives need to offer a unique starting point for an integrated analysis of complex, highly dynamic rural contexts. From this point, livelihood practices are seen as embedded actions and livelihood is considered more a process than a system. Livelihood research should capture the dynamics at play and make visible the interaction between people and their environments, as well as considering how these change over time (Kaag et al. 2013).

As mentioned above, the livelihood perspective is indeed useful for studying rural development issues. At the same time, there are still ways forward to be explored. For example, attention should be paid to the effect of globalization on livelihoods which leads to the formation of transnational networks, various forms of rural/urban linkages, and the emergence of new forms of social and cultural bonds (Kaag et al. 2013).Thus, globalization appears to offer a new round with new opportunities for livelihood (Mago, 2018). In this light, globalization may have two important consequences with respect to livelihood strategies: (1) because markets and social relations are becoming world-wide, livelihood will become multi-local; (2) because of globalization, the importance of the international and the regional-local levels of scale will increase to the detriment of the national level. The general picture of livelihood under globalization will therefore become one of increased rearrangements of strategies using various capitals in different locations. With globalization, the multi-locality of rural livelihood accelerates while becoming increasingly dependent on institutional network, social networks, information networks, etc.

The investigation done by Arato, Speelman, \& Huylenbroeck (2016) emphasises that with rural development non-related business firms will also benefit with the advancement along with the MNCs contributions to the host nation. It was concluded through this investigation that in order to become a good corporate citizen following over-regulated processes will hinder social benefits to the local community and therefore CSR projects should be carefully selected and should not be executed as a marketing tool. Encouraging local producers and supporting 
their business activities will strengthen the integration of the value chain which will establish a long-lasting linkage between rural community and MNCs. Establishing an effective communication channel, promoting health and nutrition among the community, effort of proving micro finances, creation of employment opportunities, educating technical and operational aspects of the entity activities were the factors analysed by this study.

Drusilla, Alan, \& Robert in 2002 study concluded that MNCs enter developing countries and exploit labour enjoying cost reductions at the expenses of creating job opportunities. These contributions towards the economy through the generation of jobs are less compared to the profit earned by parent companies. The study conducted by Frynas (2005) show evidence that MNCs cause 'Dutch Disease' which hinders the growth of the country by an of increase of inflows of foreign exchange via exports making agricultural and manufacturing products expensive. Also, the study highlights MNCs would try to address micro level problems but avoid addressing macro level problems. Haller (2016) concludes, through the operations of MNCs domestic economic agents are discouraged by the vigorous competition and the economic flow disrupted. The study also highlighted that investments of MNCs is highly concentrated in the proximity of the capital city and the real benefit of investment will not flow to other regions and emphasized most of the investments are not sustainable investments. Due to these research gaps identified by the authors about the positive and negative impacts researchers wanted to examine the role of MNC in the given context.

\section{Research Method}

According to the purposes of this study, the population for the study was dairy farmers who were directly engaging with the selected MNC operating in the rural community of Sri Lanka. The selected MNC has been operating in Sri Lanka since 1906, over a century, contributing 19 billion rupees to the economy annually. The MNC's vision in agriculture operations is to link farmers with their consumers by delivering healthy products while contributing to rural development by uplifting the rural livelihoods of farmers while MNCs striving for sustainable development. The twenty-five respondents for the study were selected from rural areas where dairy is supplied for the MNC in the regions of Wayamba and Northern regions. The main reason for selecting the two regions was the fact that these are the two regions which generates highest amount of milk production (Department of Census and Statistics). The sample represented both male and female, large scale and small-scale farmer operations and importantly it 
included farmers whose main source of income was generated through dairy farming and farmers who make an extra income from dairy farming. In the meantime, experience and number of years of dairy farming was considered to get a wide range of insights. Finding the purposeful sample was a hardship faced by the researchers and two pilot projects in the two regions supported facts to select the suitable sample for the interview session to get diverse insights to make the research study successful.

The research study took an exploratory approach and qualitative data were gathered. The primary data needed for the investigation was collected through the semi-structured interviews while a questionnaire was designed in English which was supported by Sinhala and English translators for effective communication purposes. Semi-structured interviews gave an opportunity to manage time effectively obtaining the insights from the dairy framers. The sessions provided the opportunity to obtain information on aspects which were unscathed in previous researchers and discovering hidden roles of the MNC contributing to the upliftment of the rural livelihoods of the dairy farmers.

Acknowledging the studies of Arato et al. (2016), Ibañez (2015) and Ng'eni et al. (2015), the semi-structured interview questions were designed guaranteeing high level of accuracy, relevancy and measurability aiding the investigation. The interview protocol consisted questions on the knowledge about dairy farming technology, how effective the training received from the MNC was and the practice of training and knowledge been applied in day- to- day routine activities. what was gained through engaging with MNCs, what was done differently after involving with MNCs; the impact of the effectiveness of the involvement of MNCs on the individual and others living in the area, the awareness of development programs initiated by MNCs and the effectiveness of those programs in enhancing the rural livelihoods of the dairy farmers, what programs and tasks can improve the state of engagement of the MNC, the support and provision of information and training shared by the MNC which is useful for sustaining the current scale and expanding in the future.

The interviews with the farmers were tape recorded and, notes were taken to maintain accuracy in the transcriptions. The participants shared information with personal experiences and details were translated to English where most of the interview sessions were conducted in Sinhala. Interviews lasted 45 minutes to 60 minutes and the transcripts were organized under themes to identify the roles of the MNC in enhancing rural livelihoods of the dairy farmers. 
The data analysis of the interviews was conducted in three phases; data reduction, data categorization and conclusion drawing (Strauss and Corbin, 1990). First, the notes were analyzed to capture the respondents' overall perspectives. Interviewed data was carefully examined based on the similarities and differences of the answers provided for the interview questions. In order to reduce the data, codes were further developed for further sorting. Secondly, coded data were recorded into a coherent pattern, which highlighted the emerging points. Third, the master map was reviewed, and the emerging points were grouped prior to finalising the thematic map which defined key themes. Investigator triangulation was employed for ensuring that the responses, data coding and data analysis is robust, valid, and reliable. Initially, the author who conducted the interviews and discussions performed these three phases individually. Next, both the authors shared their notes and repeated the three phases. Finally, a comparison was made on the two results and the authors identified and finalised key themes.

\section{Results}

A total of 25 interviews were conducted until the authors noted the emergence of saturation of themes (Saunders et al., 2017). The interview participants ranged less than one year to thirty plus years engaging in dairy farming with the blend of male and female farmers. Different backgrounds and levels of experience paved the way to get better insights about the expectations of dairy farmers regarding the engagement of the MNC and their views of the level of satisfaction with the relationship between the MNC along with the actions and roles executed by the global body.

Eighty percent of the respondents were male, and it was observed that there is a considerable amount of female involvement in the industry in the Northern region compared to the Wayamba Region.

Only thirty six percent of the farmer participants' main source of income was dairy farming while the rest of the farmers engaged in dairy farming to make an additional source of income which assisted them in stabilizing their family income while meeting their daily needs and wants.

It was observed and identified many of the respondents had minimum experience of five years in engaging in dairy farming and there was an instance a farmer having experience of 40 years thus depicting the involvement of dairy farming in the livelihoods of Sri Lanka. 


\section{Activities of the MNC and Rural Livelihood Improvements}

The existence of the MNC gave hope, motivation and belief for the farmers to excel in dairy farming activities and the MNC was acting as a pillar of success. Many of the dairy farmers initially collaborated with the MNC to make an additional source of income, which has been the strength for the farmers to uplift their rural livelihoods. Farmers appreciated the service of the MNC in terms of creating a risk-free environment while improving the infrastructure facilities of the village. The majority of the farmers were engaging dairy farming to make a secondary income to stabilize their family economy.

The key activities which were identified from the study is depicted in Table 01 The main roles of the MNC were conducting social training programs, building trust and loyalty, involving through officer engagement, conducting training programs, So social awareness, developing infrastructure development, providing financial support, maintaining quality standards, corporate citizenship, and organizing technological training. These roles of MNC assisted to improve rural livelihoods as depicted in Table 02, namely financial strength, social recognition, healthy living standards and methodical working lifestyle.

Table 1: Key activities of the MNC

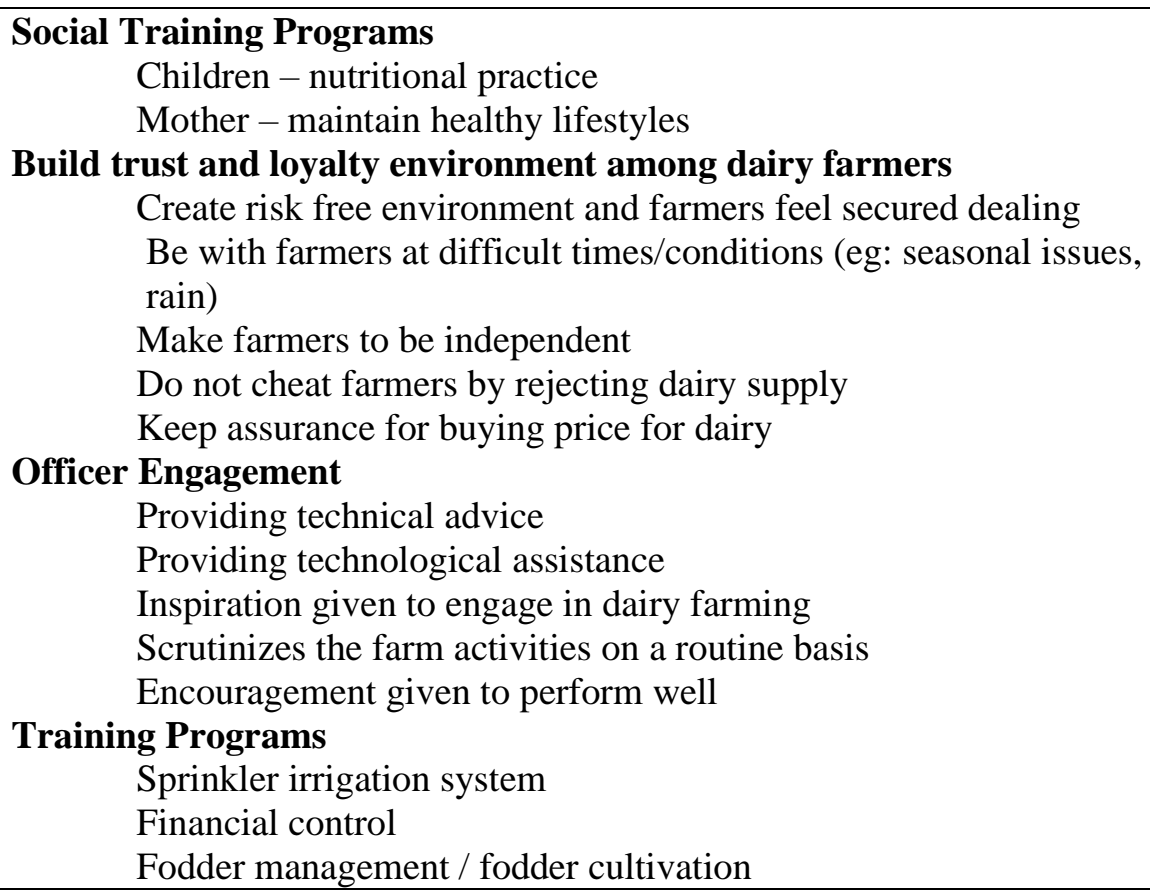




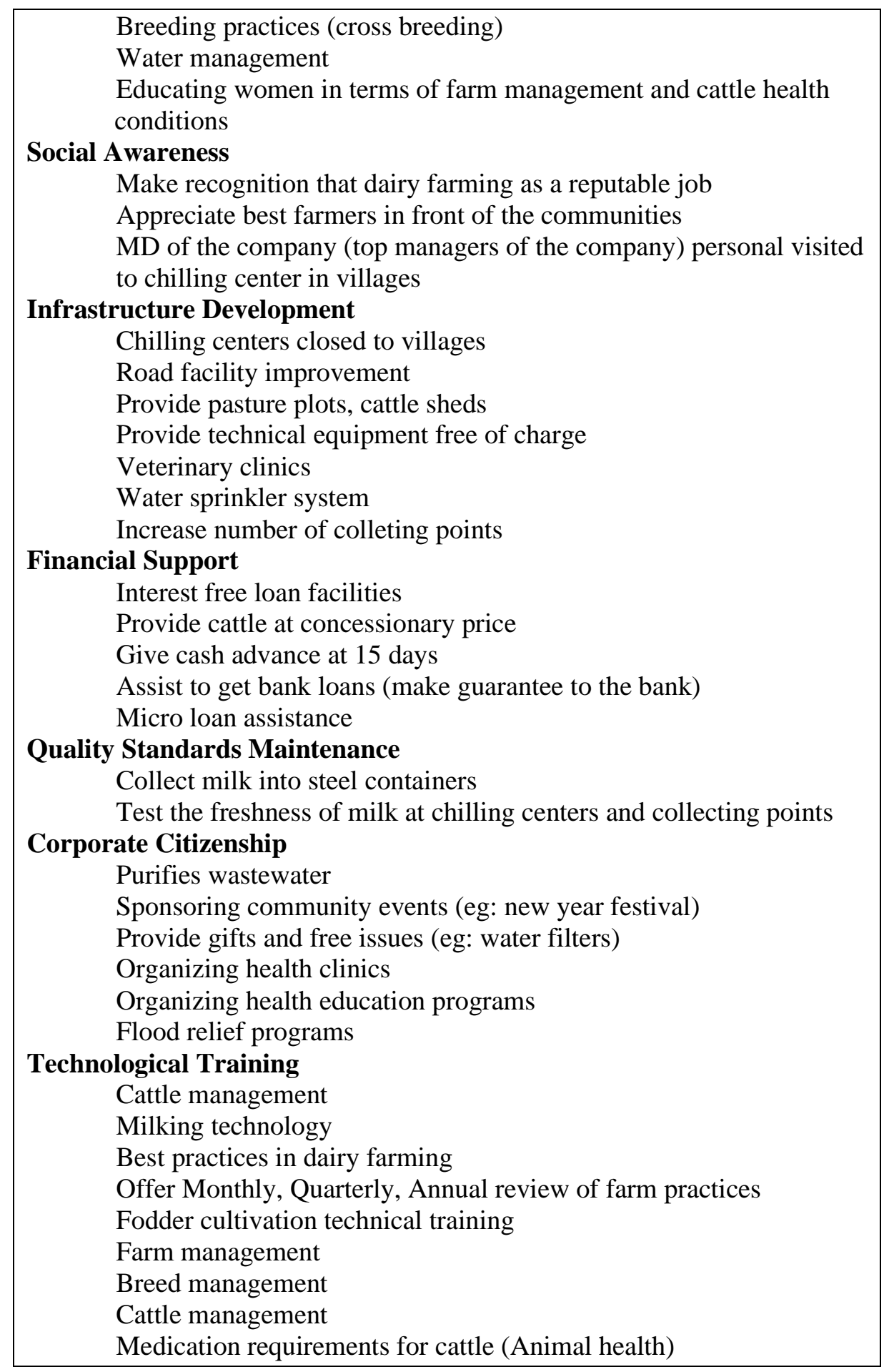


Table 2: Key areas of livelihood improvements

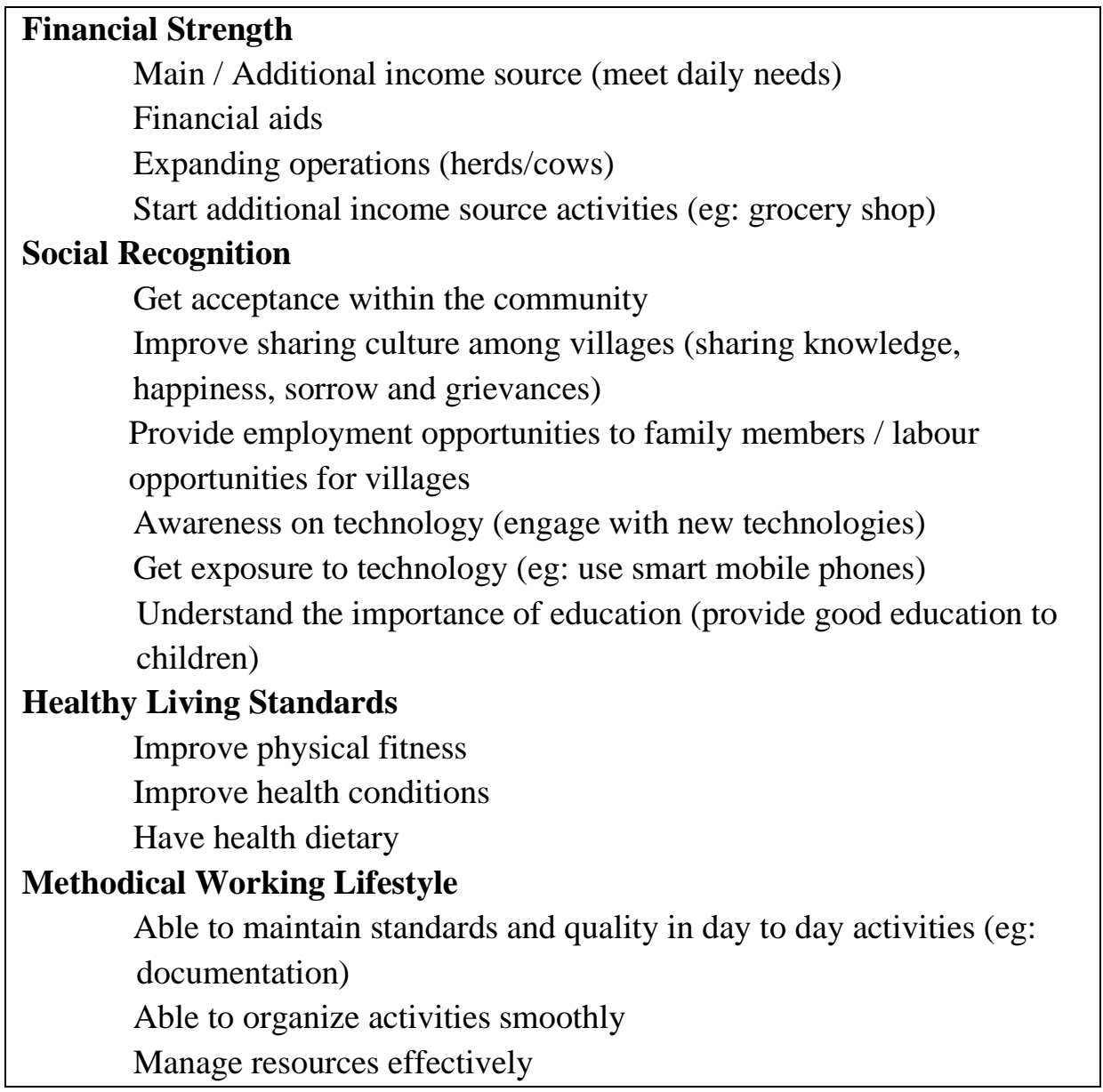

\section{Training programs}

Knowledge received from the MNC was highly appreciated by the farmers and the possession of knowledge has assisted many of the farmers in their day-to-day activities. These farmers have been applying the knowledge in other agricultural activities and have been experiencing the improvement in terms of efficiency and effectiveness in the respective trade activities. The existence of the MNC has assisted to improve the supply of dairy and practicing the same in related agricultural activities has improved the operations of the farmers in the respective fields of agriculture. Another important finding of was that after the engagement with the MNC, the farmers understood the value of quality, adhering to policies, standards and guidelines along with maintaining proper documentations. The 
farmers valuing the learning of maintaining proper records depicts how the MNC has changed the livelihoods farmers before and after the engagement with the global body. Documenting been a peculiar factor provided evidences that the role of the multinational company is shaping the livelihoods of the dairy farmers.

"I used to supply dairy for another local company about eight years ago but after engaging with the company I understood there were many things we have been doing wrong. MNC is a company which always gave prominence for quality and they made us understand why we shouldn't collect dairy into plastic containers even though it was very convenient. We learnt how to milk cows, feed them properly and respective medication to take care good care of the herd."

The farmers thus sharing their own experience illustrates that the exposure received from the MNC has motivated the dairy farmers to engage in other trade activities and farmers have experienced the effectiveness of networking with the $\mathrm{MNC}$ in local operations to expand its engagements. The knowledge received in the fields of Farm Management, Fodder Management, Cattle Management and technological exposure was highly valued by the passionate farmers. In practice, some of the participants expressed their willingness to expand trading activities making improvements and adjustments to their routine activities to overcome the difficult livelihoods faced by them.

\section{Officer engagement}

Methodically organizing activities and systemic execution of operations have been the strength of the majority of the farmers after engaging with the MNC. The farmers have been practicing these learnings in their day- to- day activities and minute operations like documentation has shown the importance of education. Most of the dairy farmers are motivated to give the best education they can afford for their children realizing the value of learning to overcome the struggle of poverty. Engaging with the MNC showed the importance of quality in any engagement and adhering to strict rules and regulations assisted the farmers to experience the improvement of the yield.

The farmers were satisfied to experience the commitment of the MNC to be deeply involved with the dairy farming community and the determination and encouragement of the field officers, the Agri-service of the MNC has helped the farmers to improve their operations. The guidance of the officers with their expertise knowledge in the field of dairy industry is an opportunity for the dairy farmer to make plans and adjustments to their operations. Meantime some of the 
farmers stressed if the MNC officers can observe the field operations before implementing and automating processes will be a greater relief because there were instances where the chilling centers were struggling with technology advancements since there was a gap between the MNC expectations and real execution process.

\section{Infrastructure development}

The farmers were happy and proud to share how the MNC has created job opportunities and paved the villagers to make an extra source of income. Collecting point manager, chilling center manager, internal route truck drivers were other opportunities created by the company. The farmers were grateful for the contributions made by the MNC in stabilizing the family income of the community and the MNC has been the greatest pillar of success of many rural dairy farmers. A farmer expressing view about the development claimed that "Animal husbandry has been the passion since I was small, my father used to milk our cows and fresh milk was consumed by all the family members. Engaging with the company helped us to make an additional income which has turned out to be our main source of income. The company is very strong which has helped many in the northern community to establish themselves after the war. The company has improved the infrastructure in terms of Chilling centres, increasing the number of collecting points which improves the quality and maintains the freshness. For a community which didn't have anything this is too much even to bear"

However, the farmers were not satisfied with the decision taken by the company to automate data recording at chilling centers. They explicitly such technological moves will not assist to overcome the contextual situation rather addressing general infrastructure problems give relief to the poor dairy farmers.

\section{Build trust and loyalty environment among dairy farmers}

The farmers from the Northern Province emotionally shared their feelings about how the involvement with the company changed their livelihoods. These farmers believe the MNC gave them the opportunity to be accepted by the society and recognized for the contributions they make. The company's existence within the region during the war and post-civil war period has been a great strength. The farmers are determined to deliver the best for the company in return for fair share of revenue. The extra source of income for these farmer families has strengthened the economic background creating a risk-free environment to live. 
"The company has played a key role in providing employment opportunities and the company has created a risk-free environment where all the farmers feel secured dealing with the company. Recently a local company promoted imported cows for farmers and now those farmers are suffering because many of those imported cows aren't conceiving, but Nestle doesn't do such things".

Accordingly, self-motivation of the farmers was the key reason to engage in dairy farming along with the MNC's trust and reputation which attracted their loyalty towards the company.

The inspiration from the Agri-service officers of the MNC has been the main driving force of these farmers and the efforts of the employees can be observed from the scale these farmers operate. The farmers admired the MNC's efforts of producing products from local raw materials and lending support for the locals. The trust and reputation gained by the company is due to the existence of the company in the dairy industry for more than 50 years and the dignified status it has maintained throughout its engagement with the dairy farmers. The farmers were satisfied with the contributions of the Agri-service officers and field officers but expected the employees at the top level to observe the field operations and make necessary implications which will help the farmers and the company both.

However, few farmers complained that the strict procedures to be followed by the small-scale farmers demotivated them due to the very small return. Apart from the technological knowledge and advancements provided the farmers expect the MNC to lobby the government and local authorities to address the infrastructure, transport facilities of the region. The coordination and cooperation between the MNC and the local authority is an important factor the farmers were stressing during the interviews.

\section{Social awareness}

Some farmers were not aware of any the projects while few farmers can recall the names of the special programs and movements organized by the MNC to uplift the community. Sponsoring Sinhala - Tamil New Year festival, which is a gala event for the villagers, was one such instance and they were passionate to discuss how the MNC treated them during the event.

"The company has played a key role in providing employment opportunities and the company has created a risk-free environment where all the farmers feel secured dealing with the company. Recently local company promoted imported 
cows for farmers and now those farmers are suffering because many of those imported cows aren't conceiving, but Nestle doesn't do such things".

The farmers reminisce the support the company provided during the floods in the past years and they were grateful for the MNC and its employees. The provision of revolving credit programs, health educational programs targeting mothers and children, veterinary clinic for the animals, free distributions of equipment for dairy farmers, promoting healthy campaigns and water management programs are some of the key development projects the farmers recalled during the interview sessions. The health-related programs, which have been very successful, has assisted many in the village to understand the gravity of health problems and the awareness programs have raised alarms within the community. The veterinary clinics have helped both the MNC and the farmers to maintain a healthy farm and to receive a quality output. The entire cost of the veterinary clinic is borne by the $\mathrm{MNC}$ and it has been a very valuable program for the dairy farming community attached to the MNC.

According to the farmers, time is a constraint for women, especially when managing an extended family. Complexity of life and prime time commitment is limiting women engagement in dairy farming in certain regions. Especially, in the Northern region it was observed that women engagement in dairy farming is higher compared to other regions and they are satisfied with the income they receive to stabilize their income and meet day -to day (needs and wants) requirements of the family. Many of the farmers highlighted the contribution of the MNC's employees was the main driving force for women to actively engage in the industry.

The engagement of women in the industry has assisted their families and during the interviews with the dairy farmers it was highlighted that the extra income gained is utilized to give a better education for their children. The participants stressed that irrespective of gender the MNC served and treated all the farmers the same, which is a positive signal and an attribute of the company. Twenty percent of the farmers interviewed were female farmers out of which three female farmers' main source of income was dairy farming. The MNC support on empowering is depicted by the number and the progress in empowerment of women supporting the rural economy.

The majority of the farmers were satisfied with the training and knowledge received from the $\mathrm{MNC}$, apart from a farmer who was dissatisfied over the training process complaining although the training could be useful there is no 
platform to practice the learning which jeopardizers the entire efforts of the MNC. The majority of the farmers express with confidence that with the knowledge they possess they can manage large scale farms and are competent enough to guide new farmers in the field of dairy farming.

The majority of the farmers interviewed had the strong motivation of expanding the business while the rest of the farmers were satisfied to operate under the current scale of operations. With the growth of the business and financial support from the MNC, the farmers are willing to increase the scale of operations. In addition to the farmers not been economically sound to expand, failure to acquire land close to the business operation was another prominent issue which has hindered the opportunity of the dairy farmers to expand.

Twenty-five farmer participants provided insights of the rural livelihoods and the roles played by the MNC in uplifting the standard of living in the local community. The farmers were emotional to express the support received from the MNC. The engagement of the MNC was healthy for the farmers via knowledge sharing, standardizing farmer operations and creating awareness. The observations and interview sessions provided evidence that there is a significant relationship with the roles of the MNC (knowledge management, initiative programs and support to empower women) and enhancement of rural livelihoods of dairy farmers by improvement of family income, more savings and investments.

\section{Discussion}

Through the interview sessions conducted with the enthusiastic dairy farmers the researchers were able to find the results supporting the literature as well as some unforeseen actions of the MNC. An overview of the findings shows that dairy farming was a secured source of income and many farmers considered the MNC was capable enough to create a risk-free environment. Some farmers expressing that they engaged in dairy farming to maintain a healthy lifestyle to gain the adequate amount of physical exercise depicts the positive impact of the MNC in the rural livelihoods.

The study carried out by Zainoddin, Amran and Shaharudin (2017) was aiming to identify the factors which can influence the development of capabilities in rural areas. It was found that Social capital improvement enhances capabilities of individuals. Three bottom line factors- Society, Economics and Environment should be catered through Human and Social welfare which will create livelihood opportunities for the individuals in Rural areas and will create a source of 
sustainable income without compromising today's needs. The study suggests that corporate organizations and NGOs should shoulder with the government to overcome the inequalities created in rural areas and to play a crucial role in building rural regions on the grounds of Economic and Social aspects to progress steadily towards Rural Development.

The MNC's training programs and sharing of expertise knowledge made the farmers understand the importance of knowledge management. This was a crucial finding during the study where the farmers identified that knowledge and technology as a powerful weapon to make their farms success. Further, the MNC's awareness programs of dairy farming knowledge motivated the farmers to educate their children with the best and the farmers has understood the importance of education to tackle poverty and improve rural livelihood is a key learning from the study. The farmers were not aware about any special program conducted by the company to empower women, but the farmers express the willingness of the company employees to encourage farmers to improve operations irrespective of $\mathrm{t}$ gender and background trade activities. Time constrains and taking care of extended families has hindered women and engaging in the industry. The farmers expressed if the company can train and empower women it will motivate families to engage in the industry and transform small scale operations into large scale operations.

Porter and Kramer (2006) stated that MNC acts as a change agent and will assist to uplift the standards of rural areas in terms of economic and social aspects. The findings of the study identified that the MNC existence paved the farmers to methodically organize their routine activities. The existence of the MNC educated the importance of knowledge and information, many of the farmers expressed during the interviews that providing the best education for their children is a dream of their life. Information processing has been a key objective in the corporate world, and it is a positive signal from the dairy farmer families equipping their children to face the future challenges boldly. The level of motivation of the farmers to give the best education to their children is a successful story of the MNC, which has been an inspiration not only for the farmers collaborating with the global institution but the entire rural community. As discussed above, the farmers expressed the MNC paved the way to make an additional source of income, the company has generated many job opportunities making the rural farmers engaging with the MNC economically sound, strengthening the economy of the Wayamba and Northern regions. 
The MNC is striving to create shared values for dairy farmers by reducing poverty, improving health and empowering people. Poverty issues are addressed through technical support, equipping with knowledge and providing financial assistance, which will assist the dairy farmers in earning a consistent income from supplying dairy to the MNC. As Kahindi et al., (2015) and Nekhwevha et al, (2018) stated, the MNC has been able to collectively achieve economic objectives by creating job opportunities, strengthening the family income by providing an additional source of income for the dairy farmer community.

The capability development will generate more benefits for the rural people; when capacity and capability are improved the cognitive thinking patterns of the individuals will be uplifted (Zainoddin et al., 2017). Accordingly, the findings of the study highlighted that capability enhancing can take place at the individual level and the group level. Lack of opportunity and resources were the main reasons for the developing countries to stagnate in terms of capability and the presence of the MNC at rural areas paved the way for the farmers to sharpen the skills and improve their performance. The enhancement of individual capabilities will assist farmers to see problems in different aspects and dimensions by been creative and innovative and this was evident with the farmers in the Northern region who are tackling post-civil war issues more rationally.

Gender equity is a strong tool of promoting inclusive growth and the researchers conducted this study to observe the role of the MNC in strengthening rural livelihoods by lending support via women empowerment (Pimpa, \& Phouxay, 2017). Women play a major role in Sri Lanka in stabilizing the family unit, by empowering women it will enhance the rural livelihoods. Empowering women from the host community and providing employment schemes will motivate the locals around the facilities of the MNCs which will reduce the socio-economic deprivations. Although there was no specific program to empower women, the employees of the MNC were trained to get the best out of the dairy farmers irrespective of the gender and background the farmer possess. Women engagement with the MNC's program enriched them with the best health and wellness information, while the educational program has inspired them to broadly investigate every aspect of their routine activities helping them to overcome poverty-stricken congestions. Male dominance was observed in the industry, but the company employees encouraged the engagement of female dairy farmers.

The MNC's operations in the Northern Region was a strength for the Tamil community who were suppressed by the government and LTTE (Liberation of 
Tigers of Tamil Eelam) during the civil war which lasted for more than three decades. During the war the MNC operated within the affected territories giving hope and belief for the villagers. During the post-civil war period, the MNC expanded its operations and assisted to uplift the social and economic standards of the villages in the Northern regions. This led the company to earn trust and loyalty among the dairy farmers and the company has been supporting unconditionally throughout during natural hazards and social issues. This finding was consisted with Porter and Kramer's (2006) definition of MNCs; that MNC as an institution which resolves social issues.

During the discussions, some farmers alerted that certain farmers do get attracted to such offers of other local company and eventually suffer the consequences of switching companies. The dairy farmers emotionally express themselves, earning an extra cent is luxury for them with the current economic and political conditions and if the MNC could make an initiative of taking care of family members by maintaining a strong welfare fund for the farmers attached to the MNCs. Meantime the farmers suggested the MNC to supply cattle feed and fodder at a concessionary price, which will help them in terms of liquidity. The MNC as a practice pays the farmers every fifteen days for the dairy supply and the rest of the competitor companies pay their farmers in less than six days. The practice of a shorter cash cycle assists the farmer to meet their basic needs since they have no investments and large savings due to the context of their livelihoods.

Moreover, the farmers suggested that if the company can provide more technological guidance, organize more awareness programs relating to "Healthy lifestyles", and organize more development programs that can improve the engagement of the farmers with the MNC. The main concern of the dairy farmers was to obtain fodder and cattle feed for a concessionary price, which will increase their profit margins. Cooperating with the local authorities will assist the MNC executing operations in the rural villages and together the institutions can contribute to the improvement of rural livelihood and rural development.

\section{Conclusion}

The study can conclude the existence of the MNC at the respective rural villages made improvements to the farmer in terms of financial strength, social recognition, healthy living standards and methodical working lifestyle. The MNC operations in the Northern region inspired people who were poverty stricken and suppressed by the civil war giving them a second chance to start from zero. Company has been the backbone encouraging the community to perform trade 
activities and the contribution from the Northern region being the highest to the company proves the effectiveness of the roles of the MNC. Presence of largescale farmers in the Northern region and the willingness of the farmers to expand further depict the interest and loyalty of the farmers towards the company.

The objective of the study was to identify the roles of the MNC (Social Training Programs, Build trust and loyalty, Officer engagement, Training programs, Social awareness, infrastructure development, financial support, quality standards maintenance, corporate citizenship, technological training) and the selected MNC has been the pioneer in addressing social issues and forming a healthy society while improving the livelihoods of the stakeholders by creating shared value. The MNC's Corporate Citizenship behavior and initiative programs have met the requirements of the community, but the continuation of such programs have been questioned by the farmers and establishing long-lasting programs will support to enhance the rural livelihoods of the dairy farmers.

Overall the MNC has been able to enhance the rural livelihoods of the dairy farmers significantly through the roles by knowledge management, execution of initiative and CSR programs and the role of empowering of women was not significant in improving the livelihoods of the dairy farmers despite the efforts of the MNC employees in encouraging women to engage in the industry. In this sense, the role of MNC to coordinate and compile a policy framework with the local authorities could play a significant role in shaping the livelihoods of the dairy farmers.

\section{Further Research Suggestions}

The future scholars can study the impact of the MNC in a different industry and their contributions towards the enhancement of rural livelihoods and bridging the rural and urban economy, not limiting to the food manufacturing company. Measures taken by a food and beverage company varies with the involvement of MNCs engaging in different industries.

This study was limited to the involvement of one particular MNC with the dairy farmers and further assessing the MNC's involvement in enhancing the rural livelihoods of coconut farmers can be assessed since coconut milk powder is an export-oriented product which is also emerging as product catering the local market. 
Due to the qualitative nature of the research the observations and conduct of semistructured interviews was limited to Wayamba and Northern region based on the demarcations of the MNC. In future, the researchers can conduct the study nationally to get a better insight of the roles of the MNC while not limiting to "Rural" livelihoods. Further conducting a quantitative research to support this qualitative research will be useful for stakeholders of this study to make strategic decisions in addressing social and economic issues discussed.

\section{Declaration of Conflicting Interests}

The authors declared no potential conflicts of interest with respect to the research, authorship, and publication of this article.

\section{References}

Addinsall, C., Rihai, N. and Nasse, A. (2019), "Agroecology and Sustainable Livelihoods as a Framework to Empower Rural Ni Vanuatu Women", SinghPeterson, L. and Carnegie, M. (Ed.) Integrating Gender in Agricultural Development, Emerald Publishing Limited, pp. 105-120.

Arato, M., Speelman, S., and Huylenbroeck, G.V. (2016), "Corporate Social Responsibility applied for rural development: An empirical analysis of firms from the American continent", Sustainability, 8, 102-119.

Central Bank Report. (2018). Annual Report Central Bank of Sri Lanka, Colombo, Sri Lanka

Chambers, R., and Conway, G. (1992), 'Sustainable rural livelihoods: practical concepts for the 21st century', IDS Discussion Paper 296, Brighton: IDS

Department of Census and Statistics. Statistics.gov.lk. (2020). Retrieved 4 September 2020, from http://www.statistics.gov.lk/Agriculture/StaticalInformation/rub13.

Drusilla, K., Alan, V., and Robert, M. (2002). "The Effects of Multinational Production on Wages and Working Conditions in Developing Countries", Presented at NBER/CEPR/SNS Conference, International Seminar on International Trade (ISIT), Challenges to Globalization, Höberge Gård, Stockholm, May 24-25.

Dunfee T. (2006), "Do firms with unique competencies for rescuing victims of human catastrophes have special obligations: Corporate responsibility and the AIDS catastrophe in sub-Saharan", Africa. Business Ethics Quarterly, 16: $185-210$. 
Engle R. (2007), "Corporate social responsibility in host countries: A perspective from American managers", Corporate Social Responsibility and Environmental Management, 14(1), 16-27.

Fougere M, Solitander N. (2009), "Against corporate social responsibility: Critical reflections on thinking, practice, content and consequences", Corporate Social Responsibility and Environmental Management, 16(4), 217 227.

Freeman, D.B. (1975), "Development Strategies in Dual Economies: a Kenyan example", African Studies Review, 18(2), 17-33.

Frynas, J. (2005). The false developmental promise of Corporate Social Responsibility; evidence from multinational oil companies. International affairs, 81(3), 581-598.

Garriga, E., and Melé, D. (2004), "Corporate Social Responsibility Theories: Mapping the Territory", Journal Of Business Ethics, 53(1/2), 51-71.

Haller, A. (2016), Globalization, Multinational Companies and Emerging Markets.Ecoforum, 5(8), 20-29.

Hiseh N. (2009), "Corporate social responsibility and the priority of shareholders", Journal of Business Ethics, 88, 553-560.

Ibañez, L. (2015), "Beyond inclusiveness: institutions, cooperation", Canadian Journal of Development Studies, 36(4), 499-515.

Igwe, P., Madichie, N. and Newbery, R. (2019), "Determinants of livelihood choices and artisanal entrepreneurship in Nigeria", International Journal of Entrepreneurial Behavior \& Research, 25(4), 674-697

Ite U. (2004), "Multinationals and corporate social responsibility in developing countries: A case study of Nigeria", Corporate Social Responsibility and Environmental Management, 11(1), 1-11.

Kaag, M.M.A., Brons, J., de Bruijn, M.E., van Dijk, J.W.M., de Haan, L.J., Nooteboom, G.and Zoomers, A. (2013), "Poverty is bad. Ways forward in livelihood research", Paper presented at the CERES 'Pathways of Development' seminar, Utrecht, 6 February

Kahindi, A.N. (2015), "Managing sustainable development through people Implications for multinational enterprisesin developing countries", Personal Review, 44(3), 388-407.

Kolk, A. and Perego, P. (2008). Determinants of the adoption of sustainability assurance statements: an international investigation, Business Strategy and the Environment, 19(3), 182-198.

Mago, S. (2018), "Migration as a livelihood strategy in Ethiopia: fallacy or reality?", International Journal of Migration, Health and Social Care, 14(3), 230-244. 
Naithani, S. and Saha, A. (2020), "Social capital and livelihood strategies in response after 2013 Kedarnath disaster (India)", Disaster Prevention and Management: An International Journal, Vol. ahead-of-print No. ahead-ofprint. https://doi.org/10.1108/DPM-07-2019-0221

Nekhwevha, F.H.,Muruviwa, A.T. and Akpan, W. (2018), "Corporate social responsibility as a drive to community development and poverty reduction: A stakeholder approach to development in Zimbabwe", The Journal for Transdisciplinary Research in Southern Africa, 14(1), 2415-2005.

Nestle Lanka PLC. (2018). Annual Report Nestle Lanka PLC. Nestle Lanka PLC. Retrieved from https://www.nestle.lk/sites/g/files/pydnoa551/files/201909/Nest1\%C3\%A9\%20Lanka\%20Annual\%20Report\%202018\%20-\%20Page s_compressed.pdf.

Ng'eni, F.B., Bukwimba, M.L., Kwesigabo, E. M., and Kaaya, I.D. (2015), “The role of Corporate Social Responsibility (CSR) in community development in Tanzania", American Journal of Economics, 5(6), 609-615.

Nwoke, U. (2016), "Two complimentary duties under corporate social responsibility: Multinationals and the moral minimum in Nigeria's Delta region", International Journal of Law and Management, 58(1), 2-25

Odebode, A. (2019), "Impacts of integrated scheme on livelihood and rural housing condition in Nigeria", World Journal of Science, Technology and Sustainable Development, Vol. ahead-of-print No. ahead-of-print. https://doi.org/10.1108/WJSTSD-05-2018-0035

Pimpa, N., and Phouxay, K. (2017), "CSR and women empowerment: A comparative study of women in the mining community in Thailand and Lao PDR", ASEAN Journal of Management \& Innovation, 4(2), 145-154.

Porter, M.E., and Kramer , M.R. (2006), "The link between competitive advantage and corporate social responsibility", Harvard Business Review, 12, 78-92.

Saunders, B., Sim, J., Kingstone, T., Baker, S., Waterfield, J., Bartlam, B. and Jinks, C. (2017), "Saturation in qualitative research: exploring its conceptualization and operationalization", Quality \& Quantity, 52(4), 1893 1907.

Scoones, I. (2009), "Livelihoods perspectives and rural development", The Journal of Peasant Studies, 36(1), 171-196

Scoones, I. and W. Wolmer, eds. (2003), "Livelihoods in crisis? New perspectives on governance and rural development in Southern Africa", IDS Bulletin, 34(3), 15-26. 
Sotorrio L, Sanchez J. (2010), "Corporate social reporting for different audiences: The case of multinational corporations in Spain", Corporate Social Responsibility and Environmental Management, 17, 272-283.

Strauss, A. and Corbin, J. M. (1990), Basics of qualitative research: Grounded theory procedures and techniques, Sage Publications, Inc.

Tsoi J. (2010), "Stakeholders' perceptions and future scenarios to improve corporate social responsibility in Hong Kong andMainl and China", Journal of Business Ethics, 91(3), 391-404.

Williams, P.A., Frempong, G.K., Akuffobea, M., and Onumah, J.A. (2017), "Contributions of multinational enterprises to economic development in Ghana: A myth or reality?" International Journal of Development and Sustainability, 6(12), 2068-2081.

Zainoddin, A., Amran, A., and Shaharudin, M. (2017), "Factor That Impacts the Capability Development and Sustainable Income of the Rural Development Programme in Malaysia", Advanced Science Letters, 23(11), 10621-10624. 